\title{
Stent Application for the Treatment of Cerebral Aneurysms
}

\author{
Byung Moon Kim, MD, PhD, Dong Joon Kim, MD, PhD, Dong lk Kim, MD, PhD
}

Rapid and striking development in both the techniques and devices make it possible to treat most of cerebral aneurysms endovascularly. Stent has become one of the most important tools in treating difficult aneurysms not feasible for simple coiling. The physical features, the dimensions, and the functional characteristics of the stents show considerable differences. There are also several strategies and tips to treat difficult aneurysms by using stent and coiling. Nevertheless, they require much experience in clinical practice as well as knowledge of the stents to treat cerebral aneurysms safely and effectively. In this report, a brief review of properties of the currently available stents and strategies of their application is presented.

Key Words : Intracranial aneurysm; Stent; Endovascular Procedures

Endovascular treatment becomes a main stream for the treatment of both ruptured and unruptured cerebral aneurysms. Rapid and striking advances in both the techniques and devices make it possible to treat most of cerebral aneurysms endovascularly. Since Higashida et al. first reported the use of a balloon-expandable coronary stent as a scaffold for coiling of basilar artery aneurysm in 1997 [1], several pathfinders have applied balloon-expandable stents to uncoilable lesions such as dissecting, fusiform or wide-necked aneurysms [2-5]. However, several limitations and inherent risks of the balloon-mounted stents prohibited general acceptance

\footnotetext{
All authors: Interventional Neuroradiology, Department of Radiology, Yonsei University College of Medicine Severance Hospital, Seoul, Korea

Received May 3, 2011;

accepted after revision July 12, 2011.

Correspondence to: Byung Moon Kim, MD, PhD, Interventional Neuroradiology, Department of Radiology, Yonsei University College of Medicine Severance Hospital, 50 Yonsei-ro, Seodaemun-gu, Seoul 120-752, Korea.

Tel. 82.2.2228.7400 Fax. 82.2.393.3035

E-mail: bmoon21@hanmail.net

This is an Open Access article distributed under the terms of the Creative Commons Attribution Non-Commercial License (http://creativecommons.org/licenses/by-nc/3.0) which permits unrestricted non-commercial use, distribution, and reproduction in any medium, provided the original work is properly cited.
}

of the stent-assisted coiling technique. Since the $1 \mathrm{st}$ self-expanding stent (Neuroform) had been introduced and approved to assist the coil embolization in 2001, stent has become one of the most important tools in treating difficult aneurysms not feasible for simple coiling [6-8]. At present, 5 types of stents dedicated for intracranial use are available in the worldwide market: 4 stents (Neuroform, Solitaire, Enterprise, and Leo plus) for assisting coiling and 1 stent (Wingspan) for the treatment of intracranial atherosclerotic disease. Except for the Leo plus, 4 types of stents are currently available in our country. The physical features, the dimensions, and the functional characteristics of these stents show considerable differences [9]. There are also many strategies and tips to treat difficult aneurysms by using stent(s), with or without coiling [10-26]. It is assumed that, in individual cases, interventional neuroradiologists or neurosurgeons follow their personal preferences, and which stent and how it is used may be decided according to their clinical experience. Nevertheless, they require much experience in clinical practice as well as knowledge of the stents to treat cerebral aneurysms safely and effectively. In this report, a brief review of properties of the currently available stents and strategies of their application is presented. 


\section{Stent Design and Physical Properties}

Knowledge of stent design and physical properties should help physicians in choosing more appropriate stent for both the given vascular anatomy and clinical purpose, and may enable to anticipate its behavior and potential problems. Except for Leo plus stent which is made by wire braiding, all stents are laser-cut from nitinol hypotube. Therefore, foreshortening of these stents is minimal and is clinically negligible. Stent cell design can be divided into open-cell (Neuroform, Wingspan) and closed-cell (Enterprise, Solitaire, Leo plus) types and may affect the physical properties. Several features can be used to characterize physical properties of the stents. Krischek et al. recently studied to characterize physical properties of the currently available stents [9], which are summarized in the following paragraphs.

1) The radial force corresponds to the force that the stent exerts on the vessel wall and that enables to support the coils inside an aneurysm (Fig. 1). This is an important factor when a stent is used for the purpose of a scaffold for coiling. It can be measured during compression of the 2 plates at $50 \%$ of the labeled diameter of the stent. In terms of the radial force, Wingspan stent has the highest radial force, followed by Solitaire, Enterprise and Neuroform ${ }^{3}$.

2) Chronic outward force (Outward radial force) is changes in diameter vs. force for both expansion and contraction during circumferential compression of the stent throughout $360^{\circ}$ (Fig. 2). In terms of chronic outward force, Wingspan has the highest force, followed by Neuroform ${ }^{3}$, Solitaire, and Enterprise at about $85 \%$ of the labeled stent diameter. Generally, at higher oversizing, the closed-cell design stents tend to exhibit a higher radial force than open cell design stents. Solitaire shows higher radial force at higher oversizing while Neuroform ${ }^{3}$ shows higher radial force at lower oversizing.

3) The wall apposition describes a stent's ability to

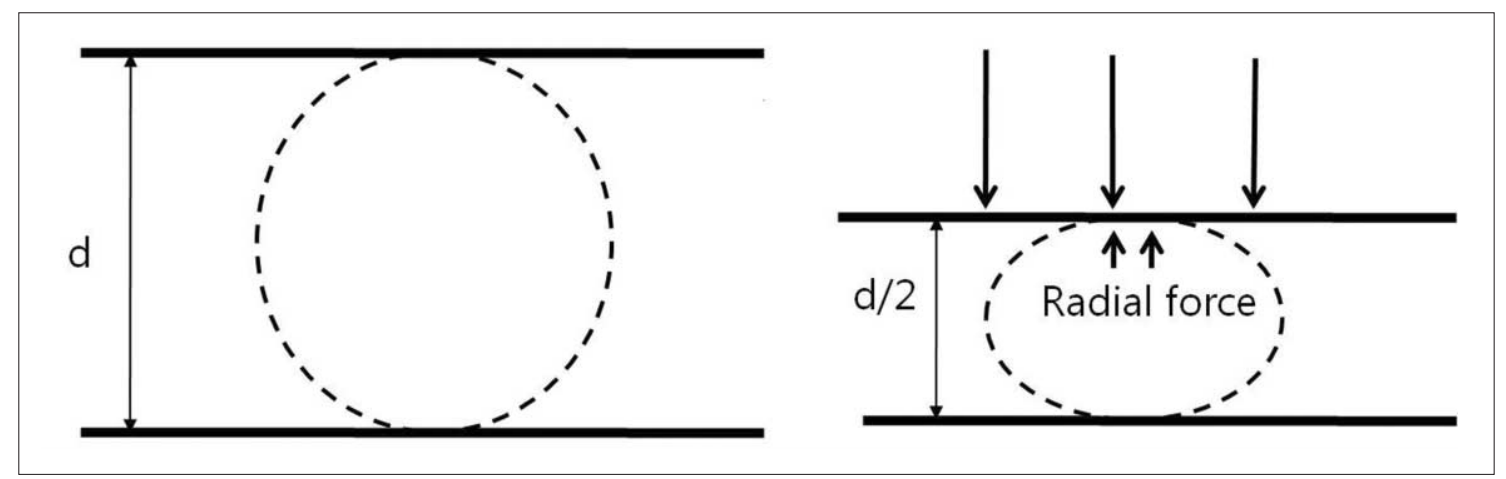

Fig. 1. Radial force measured by two plate method.

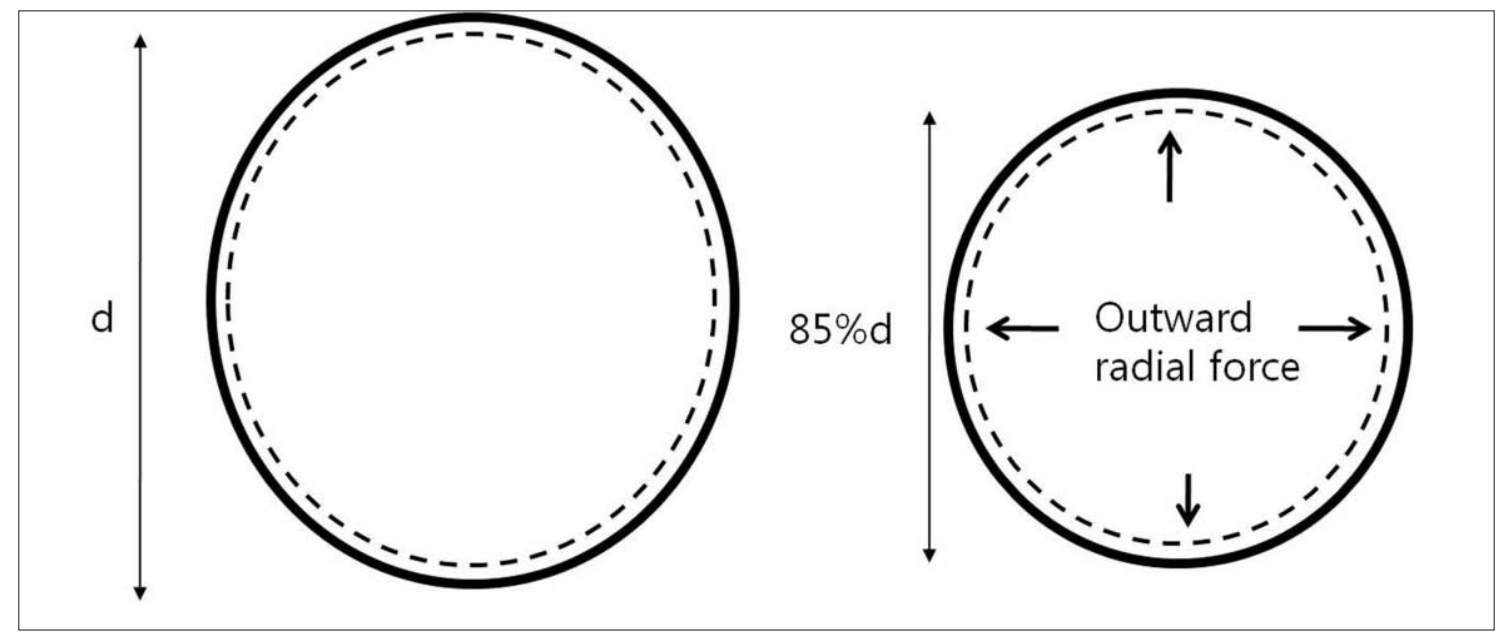

Fig. 2. Outward radial force measured by thin film method. 
remain in close contact with the adjacent vessel wall when deployed in a curved vessel. Open-cell design stents (Neuroform ${ }^{3}$ and Wingspan) are superior to closed-cell design stents in terms of wall apposition. Among the closed-cell design, Solitaire is better than Enterprise.

4) Conformability describes a stent's ability to adopt the tortuous path of a vessel, instead of forcing the vessel to straighten. It is indirectly measured by bending stiffness, and higher bending stiffness means less conformability. Enterprise has the highest bending stiffness, followed by Solitaire, Wingspan, and Neuroform ${ }^{3}$.

5) Gator backing describes a stent's tendency to flair its struts outward, forming protrusions into convexity. Excessive gator backing may result in strut's protrusion into the aneurysm sac at the convexity of the vessel, leading to poor prevention of coil herniation into the parent artery. Only open-cell design stents (Neuroform and Wingspan) reveal a gator backing phenomenon.

6) Kinking is the buckling of a stent when it is bent over a curve (Fig. 3). Excessive kinking of a stent leads to difficulty in catheter navigation through the deployed stent. Open-cell type stents (Neuroform and Wingspan) may reveal kinking in proportion to the degree of the vessel bending.

7) Ovalization describes the phenomenon of the stent

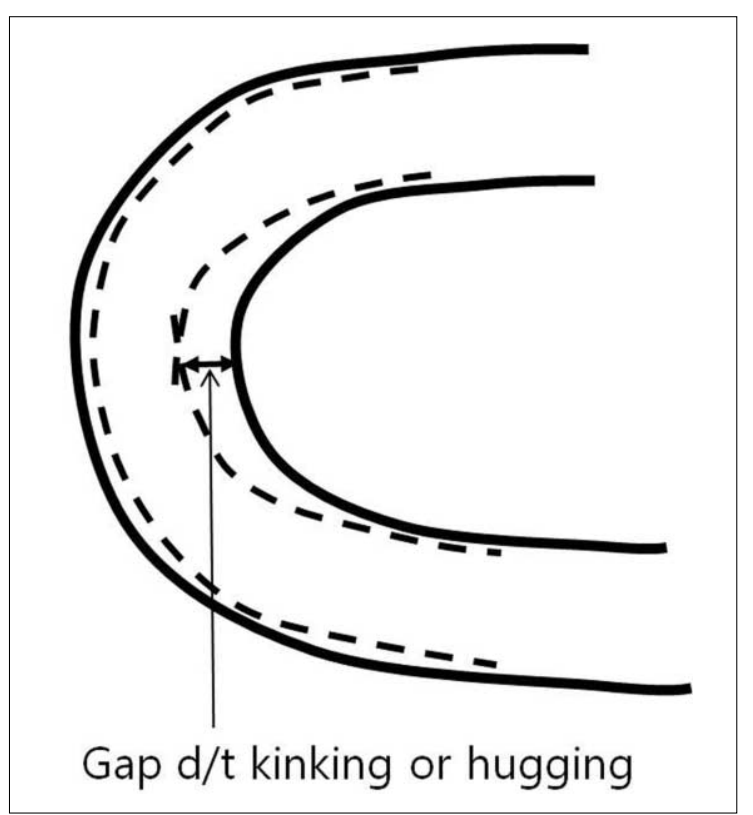

Fig. 3. Kinking or hugging lumen flattening when it is curved (Fig. 4). Enterprise ovalizes the most, followed by Neuroform, Solitaire, and Wingspan.

8) The cell size means the area between a stent's struts. Solitaire has the largest cell size, followed by Neuroform $^{3}$, Enterprise, and Wingspan.

9) Except for Wingspan stent, the methods of delivery are currently similar because the latest version of Neuroform (Neuroform EZ) employed delivery system similar to that of Enterprise. However, Neuroform EZ still requires a higher profile microcatheter $(0.027$-inch microcatheter) than Enterprise or Solitaire (0.021-inch microcatheter).

\section{Technical Considerations}

\section{1) The sequence of using a stent and a microcatheter}

a) Through the struts vs. jailing technique

When stent-assisted coiling is performed, the technique of catheter tip placement into the aneurysm sac can be divided into 2 methods, catheter jailing and through the stent's strut technique [11]. The choice between the two methods may depend on the practicing physician's experience. In my experience, jailing technique has several advantages over through the strut technique. First, catheter placement into the sac is more difficult after stent deployment than before, especially for closed and small-sized cell design stents such as an

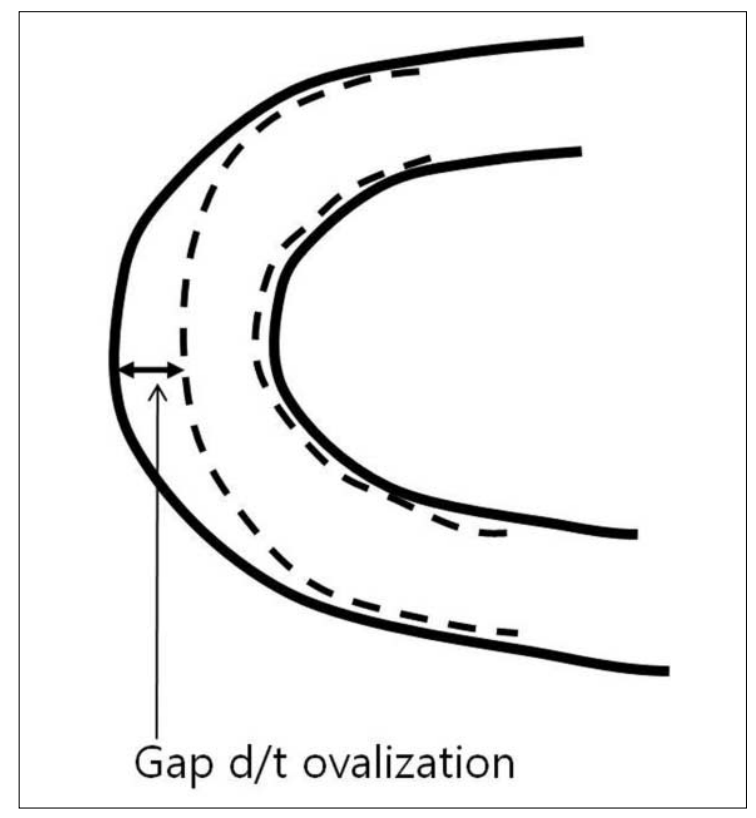

Fig. 4. Ovalization 
Enterprise. Second, like a balloon, the deployed stent prevents the kickback of the jailed catheter during coiling. Third, coil herniation into the parent artery is less likely to occur in the catheter jailing technique. Finally, inadvertent raveling of coils around the struts may more be avoidable. One drawback of the catheter jailing technique is that the catheter tip is extruded from aneurysm sac during stent deployment. One solution of such a drawback is deploying of several coil loops before stent placement (Fig. 5). Pre-deployed coil loops can be used as a guidewire and may allow reintroduction of microcatheter tip into the sac.

\section{b) Semi-jailing}

Semi-jailing technique can be performed by using fully (Solitaire) or partially (Enterprise) retrievable stent $[12,13]$. A stent is partially or fully deployed, bridging the aneurysm neck and coiling is performed. After completion of coiling, the stent can be either retrieved (Fig. 6) or permanently placed (Fig. 7). There are two theoretical advantages in this technique. First, unlike balloon-assisted coiling, blood flow arrest does not occur during the coiling, and second, antiplatelet medication is not required if the stent is retrieved after completion of coiling, which is a very attractive option for the treatment of ruptured aneurysms. One possible
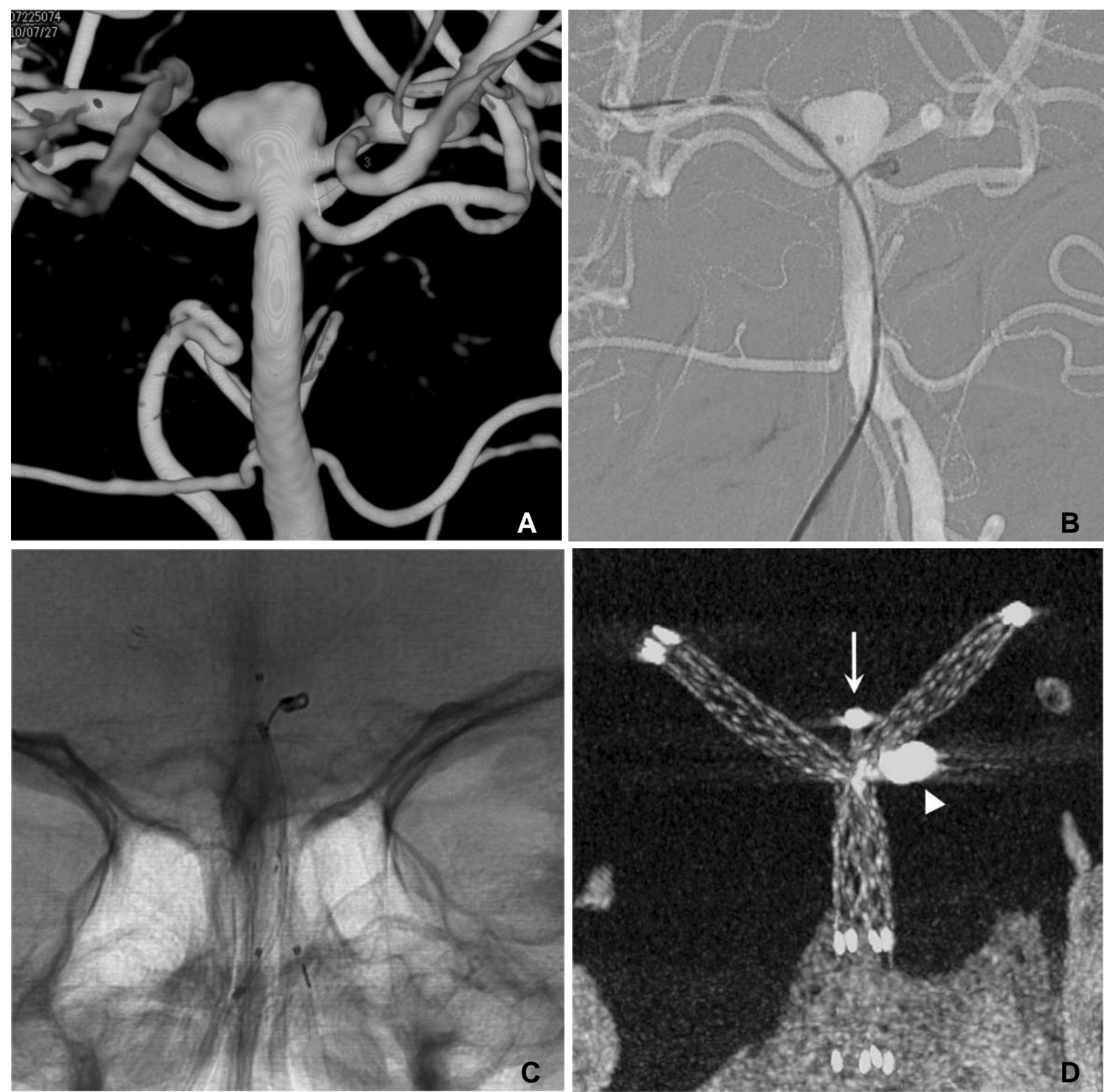

Fig. 5. A. Two aneurysms at the basilar artery (BA) tip and BA-superior cerebellar artery (SCA).

B. Several coil loops are deployed in the SCA aneurysm sac before stent deployment.

C. After stent deployment, the extruded catheter tip is re-inserted into the sac over the pre-deployed coil loops.

D. Complete coiling is performed after Y-stenting through the struts. Arrow head indicates coil mass in the BA-SCA aneurysm and white arrow indicates the catheter tip located in the BA aneurysm sac. 


\section{Stent Application for the Treatment of Cerebral Aneurysms}

concern is that the detached coil loops may herniate or migrate, hanging on stent struts during the stent retrieval.

\section{c) Stent-jack technique}

Stent-jack technique can be applied to a very small aneurysm that catheter tip introduction into the sac looks very risky. First, a 0.021 -inch microcatheter is navigated to the distal portion of the parent artery, crossing the aneurysm neck. The tip of another microcatheter is placed near the aneurysm neck facing the dome. Second, a coil is fully deployed but not detached. And then a preloaded stent in the prepositioned microcatheter is deployed to push the predeployed coil loops into the sac, and the coil is detached finally [22].

\section{2) Stent deployment technique}

Although there are some degrees of difference according to their design, all stents show ovalization
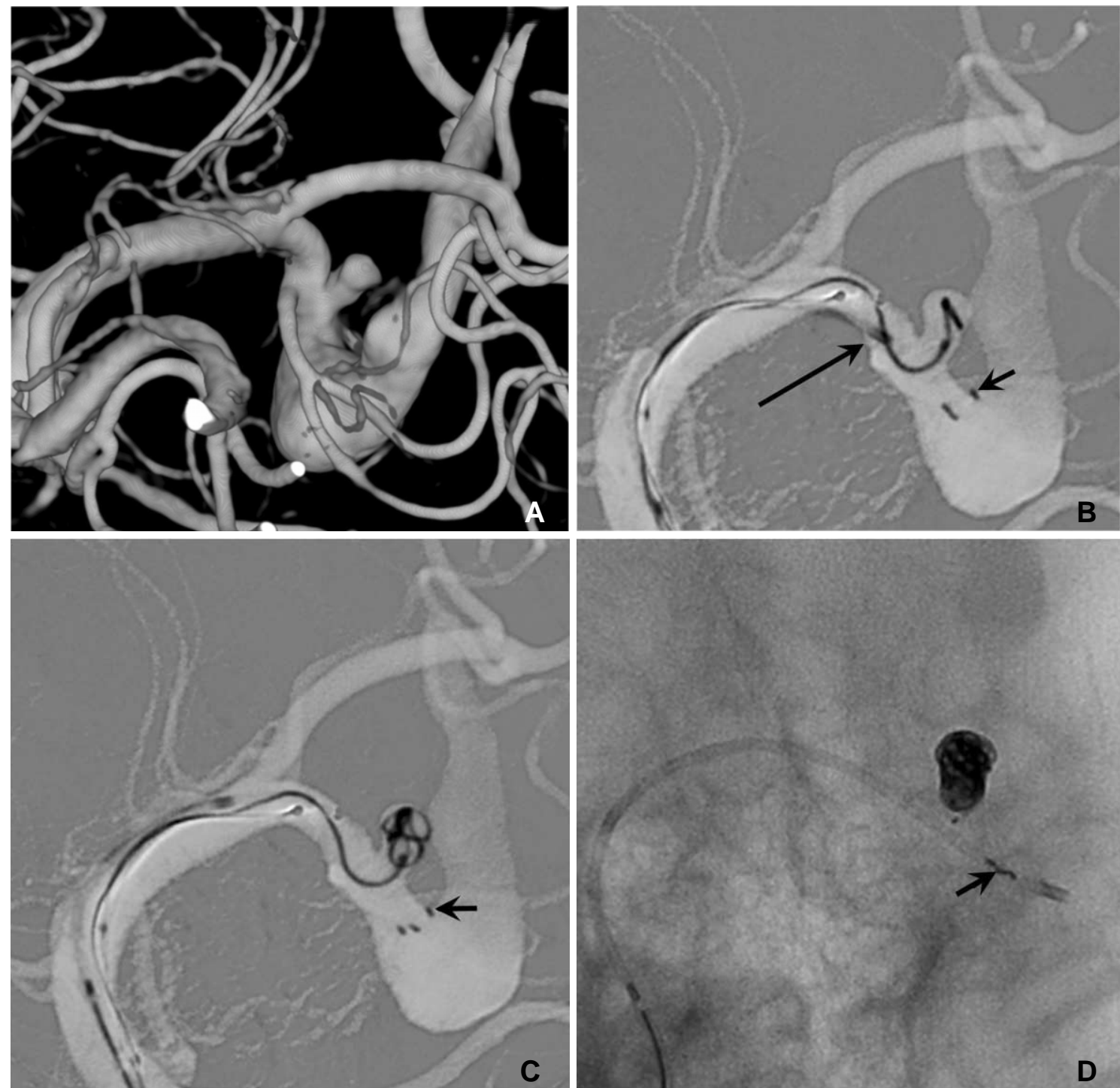

Fig. 6. Semi-jailing technique.

A. A saccular aneurysm at the left middle cerebral artery (MCA) inferior division proximal portion, and a fusiform aneurysm of the inferior division just distal to the saccular aneurysm.

B. A Solitaire stent is partially deployed after partial deployment of coil loops. A short arrow indicates distal markers of the Solitaire stent and a long arrow indicates the distal tip of a Prowler plus select catheter.

C. Coiling is stably performed without catheter kickback owing to the partially deployed stent.

D. After complete coil embolization, the stent is retrieved and is removed. In this case, the stent is used for the purpose of preventing anticipated catheter kickback due to the distal flaring of the parent artery. Balloon is also anticipated to be unstable due to a distal flaring of the artery. The stent is removed after complete coiling for the further treatment of a distal fusiform aneurysm of the parent artery by using flow diverter. 
and kinking, leading to poor wall apposition. These undesirable phenomena can, to some degree, be overcome by using appropriate deployment technique. A simultaneous dynamic push (of the loading wire) and pull (of the microcatheter) technique makes it possible to avoid these phenomena [27]. Insufficient push may cause ovalization of the stent, leading to poor wall apposition along the convexity. Insufficient pull may cause kinking of the stent leading to poor wall apposition along the concavity of the vessel (Figs. $3,4)$.

\section{3) Solutions for cases that it is difficult to navigate a catheter across the aneurysm neck}

a) Coiling-stenting-coiling

Since an introduction of the separate delivery system of microcatheter and stent, the delivery of a stent to target segment to bridge the aneurysm neck has become easier, even beyond the circle of Willis. However, it is not rare to experience difficulty in navigating a microcatheter across the aneurysm neck to a distal portion or a branch of the parent artery. It is also often risky to make a labored effort to navigate a microcatheter across the neck of the unprotected aneurysm. In such a case, partial coiling can be
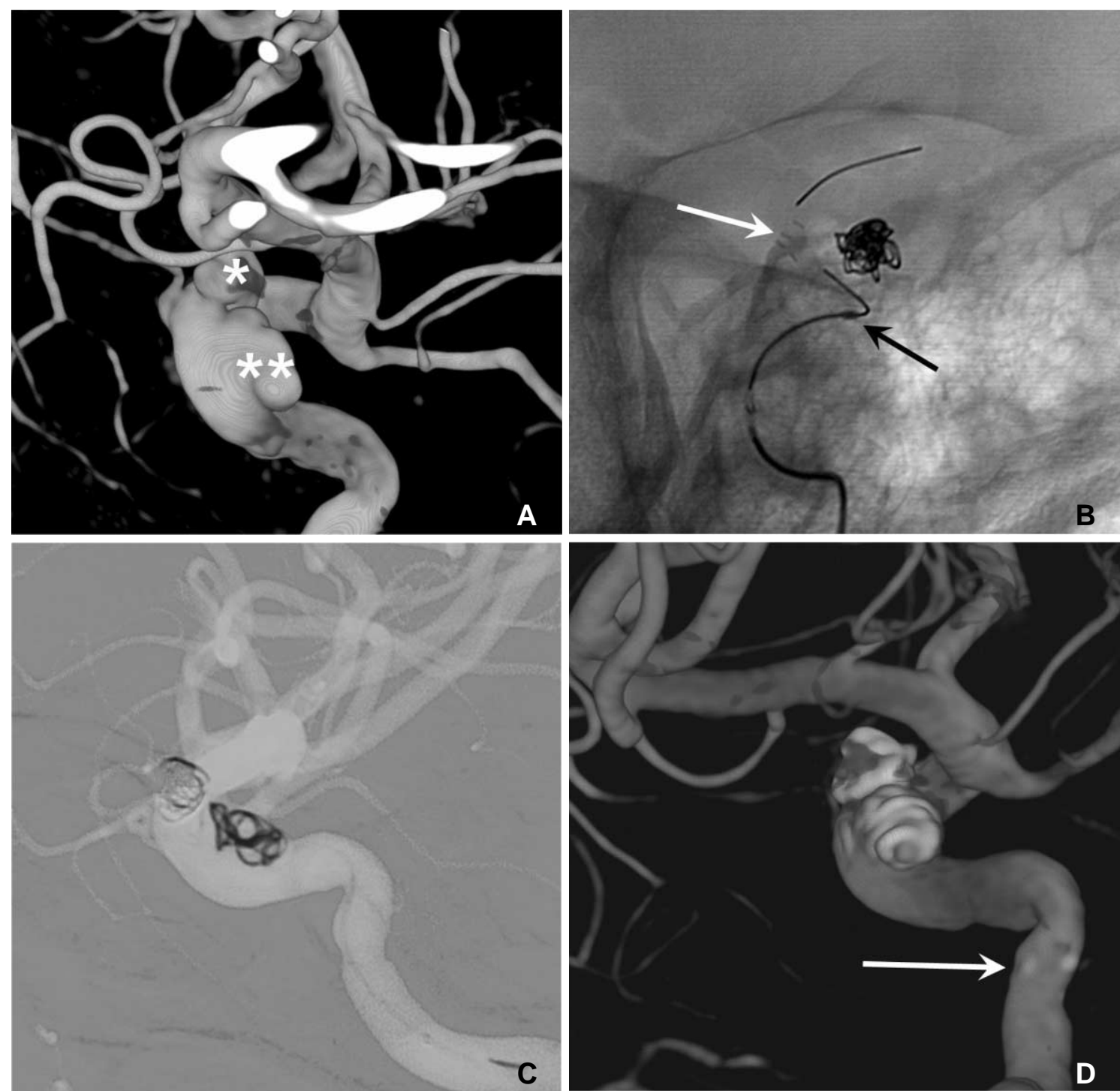

Fig. 7. A. Two aneurysms at the para-ophthalmic internal carotid artery (ICA) $\left({ }^{\star}\right)$ and cavernous ICA $\left({ }^{* *}\right)$.

B. Coiling is performed after partial deployment of an Enterprise stent (white arrow: distal marker of stent, black arrow: proximal marker of stent).

C. After completion of coil embolization of the para-ophthalmic aneurysm, the stent is partially re-sheathed. The catheter tip is repositioned into the cavernous aneurysm sac and coiling is performed after permanent placement of the stent covering both aneurysm necks. D. The 3D-reconstruction image after completion of coiling of both aneurysms. Arrow indicates proximal markers of the Enterprise stent. 
preceded to protect aneurysm dome and to divert blood flow. Partial coiling of the aneurysm may make it easier to navigate a microcatheter across the aneurysm neck and lower the risk of aneurysm rupture during the navigation of a guidewire and a microcatheter. The completion of coiling can be performed after stent placement (Fig. 8).

\section{b) Waffle cone configuration}

Another solution is stent deployment configuring a waffle cone appearance, that is, the distal end of the stent is deployed at the neck and is partially flaring into the sac so as to protect the parent artery and its branches [18, 19]. Actually, Enterprise or Neuroform
EZ stent cannot be used for this technique because of the presence of a loading safety wire. Solitaire is most suitable for this technique, although Neuroform ${ }^{3}$ stent can be used for this purpose.

\section{4) Solutions for cases that a single stent is insuffi- cient for coiling}

There are occasional cases that a single stent is insufficient to prevent coil loop herniation, to protect incorporated branch into the aneurysm sac/neck, or for both. For such cases, several solutions are suggested.

a) Stent plus multi-catheter or balloon

The advantages and usefulness of multi-catheter technique are widely discussed in the literature [28,
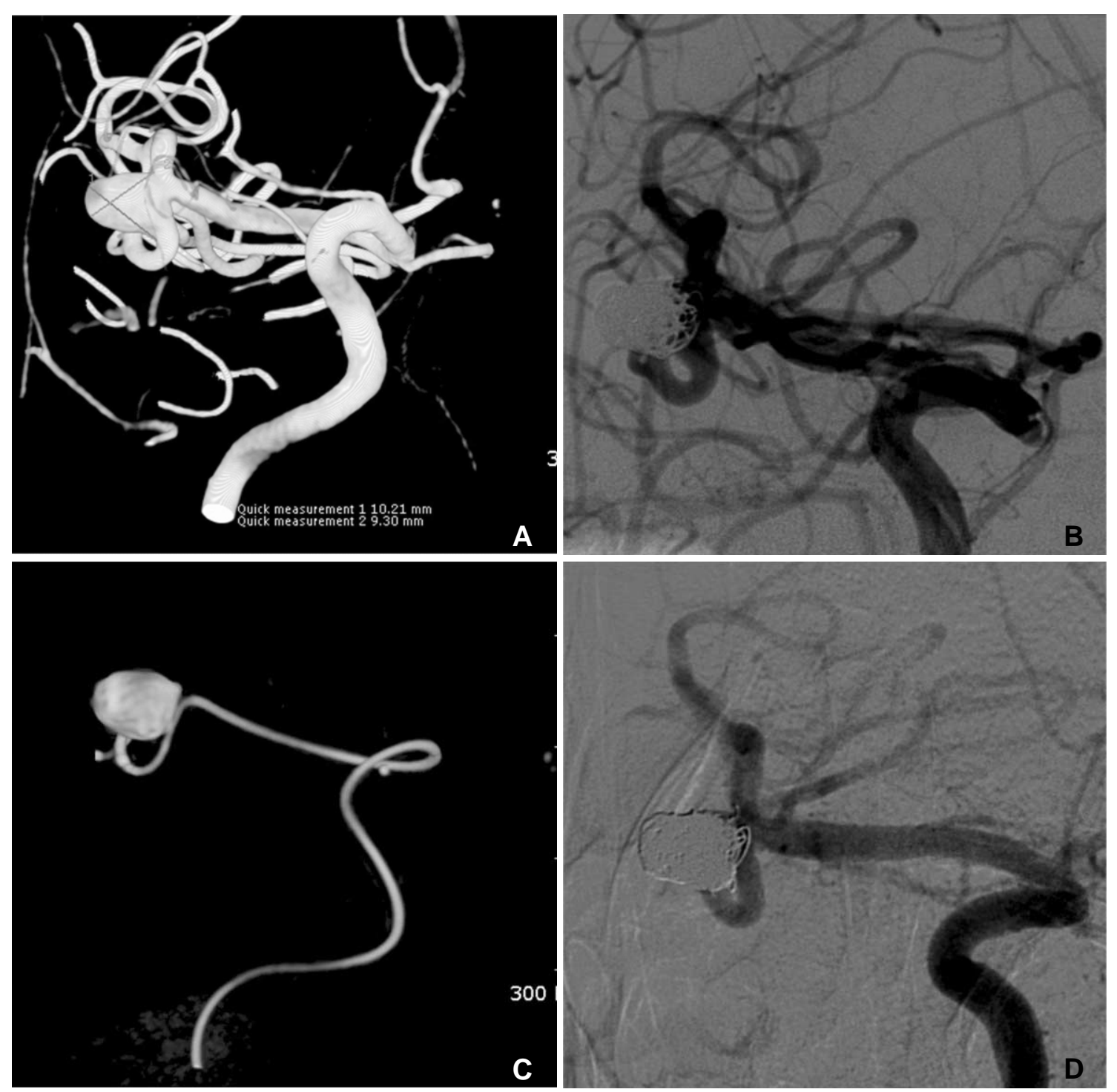

Fig. 8. A. A wide necked right MCA aneurysm.

B. Because catheterization of inferior division failed, coiling is performed with two catheters technique.

C. The catheter is easily navigated into the inferior division after partial coiling of the aneurysm sac.

D. Complete coil embolization is performed after a stent placement from M1 trunk to the inferior division. 
29]. Stent plus multi-catheter technique is simply the combination of stent-assisted technique and multicatheter technique. This technique is very useful for coiling of both the wide-necked and branch-incorporated aneurysms. Stent can prevent coil herniation into the parent artery, but cannot protect from occlusion of an incorporated branch into the sac or neck. In such a case, multi-catheter technique helps to save an incorporated branch (Fig. 9).

Balloon and stent assisted technique is that one branch is protected by a stent and the other by a balloon (Fig. 10). b) Horizontal stenting

If anterior communicating or posterior communicating artery has the capacity to permit a 0.021 -inch microcatheter navigation, horizontal placement of a single stent from anterior to middle cerebral artery or from a posterior cerebral artery (PCA) to contralateral PCA may facilitate coiling of a very wide-necked aneurysm [20, 21] (Fig. 11).

c) Two stents with Y-configuration, X-configuration, or linear configuration

For wide-necked bifurcation aneurysms, both side
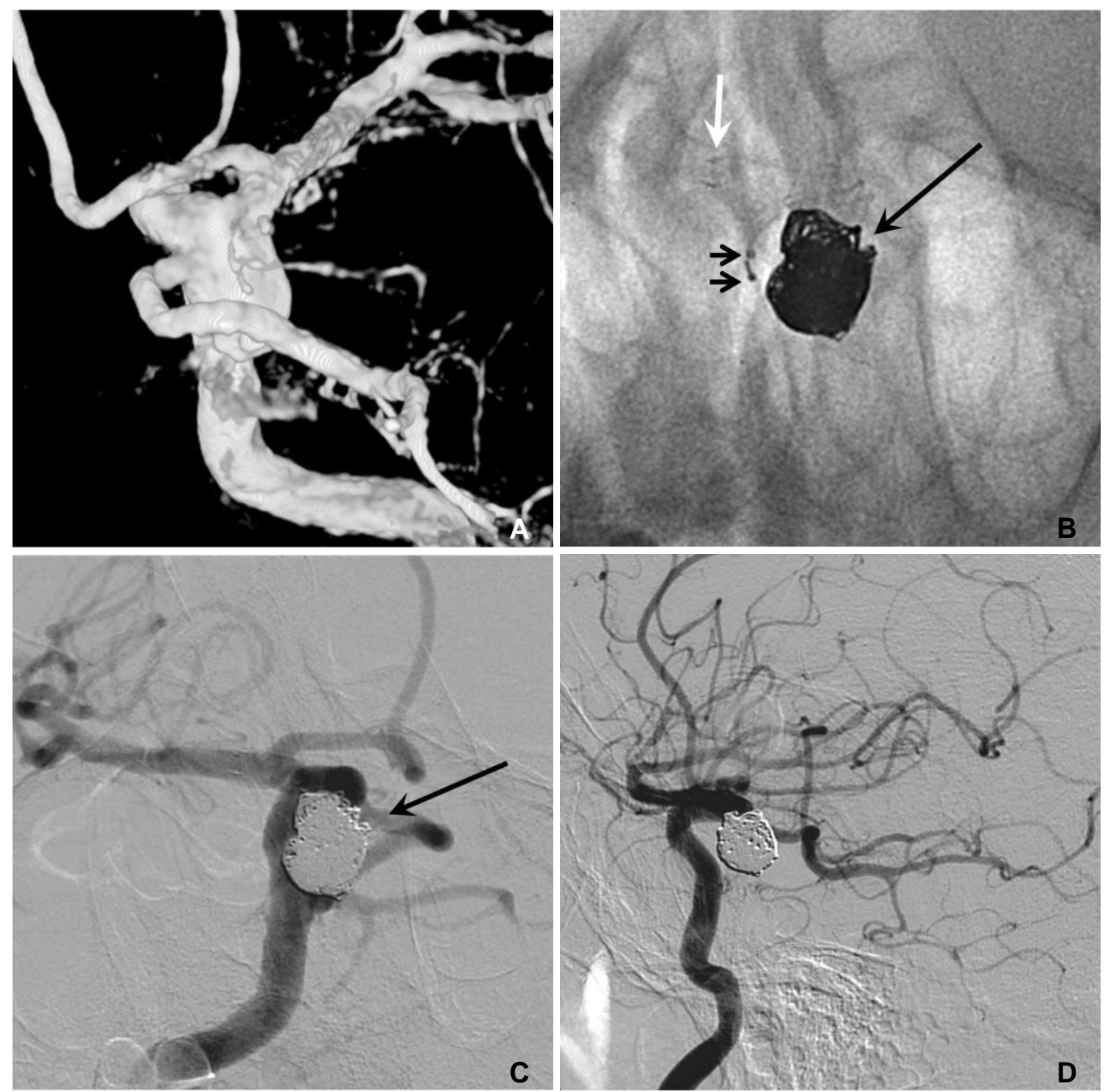

Fig. 9. A. A large aneurysm with a fetal type posterior cerebral artery (PCA) incorporated into the sac at the ICA posterior communicating artery $(\mathrm{PComA})$ region.

B. After a Neuroform stent placement, coiling is performed with two catheters technique for saving the origin of the fetal type PCA (white and long arrows: markers of stent, short arrows: distal markers of two microcatheters).

C, D. The aneurysm sac is completely embolized with saving the origin (a long black arrow) of the fetal type PCA. A white arrow indicates distal markers of the deployed Neuroform stent and short arrows indicate proximal markers of two microcatheters. 


\section{Stent Application for the Treatment of Cerebral Aneurysms}

branches can be protected by 2 stents placed in Yconfiguration. Two types of methods are possible. First, one stent is deployed to one branch, a microcatheter is navigated into the other side branch through the deployed stent's struts, and then a 2nd stent is deployed [14-17]. It is often difficult to navigate a 0.021 -inch microcatheter by using 0.014 -inch wire through the struts into the other side branch because the microcatheter tends to be trapped in the struts due to the ledge effect between the microcatheter and the wire. When a 0.016 -inch or 0.018 -inch microwire used, such a difficulty can be overcome (Fig. 12).
Another technique avoiding such a difficulty is kissing stents in Y-configuration. In this technique, two 0.021-inch microcatheters are prepositioned from the parent artery to both branches and two stents are simultaneously or sequentially deployed (Fig. 13).

The 3rd method using 2 stents with Y-configuration is that the 1st stent is deployed from one branch to the proximal parent artery and then the proximal end of the 2nd stent is positioned precisely at the bifurcation level of the parent artery (personal communication).

For a wide-necked aneurysm at the crossing 2 parent arteries, 2 stents deployment with $\mathrm{X}$-configuration is
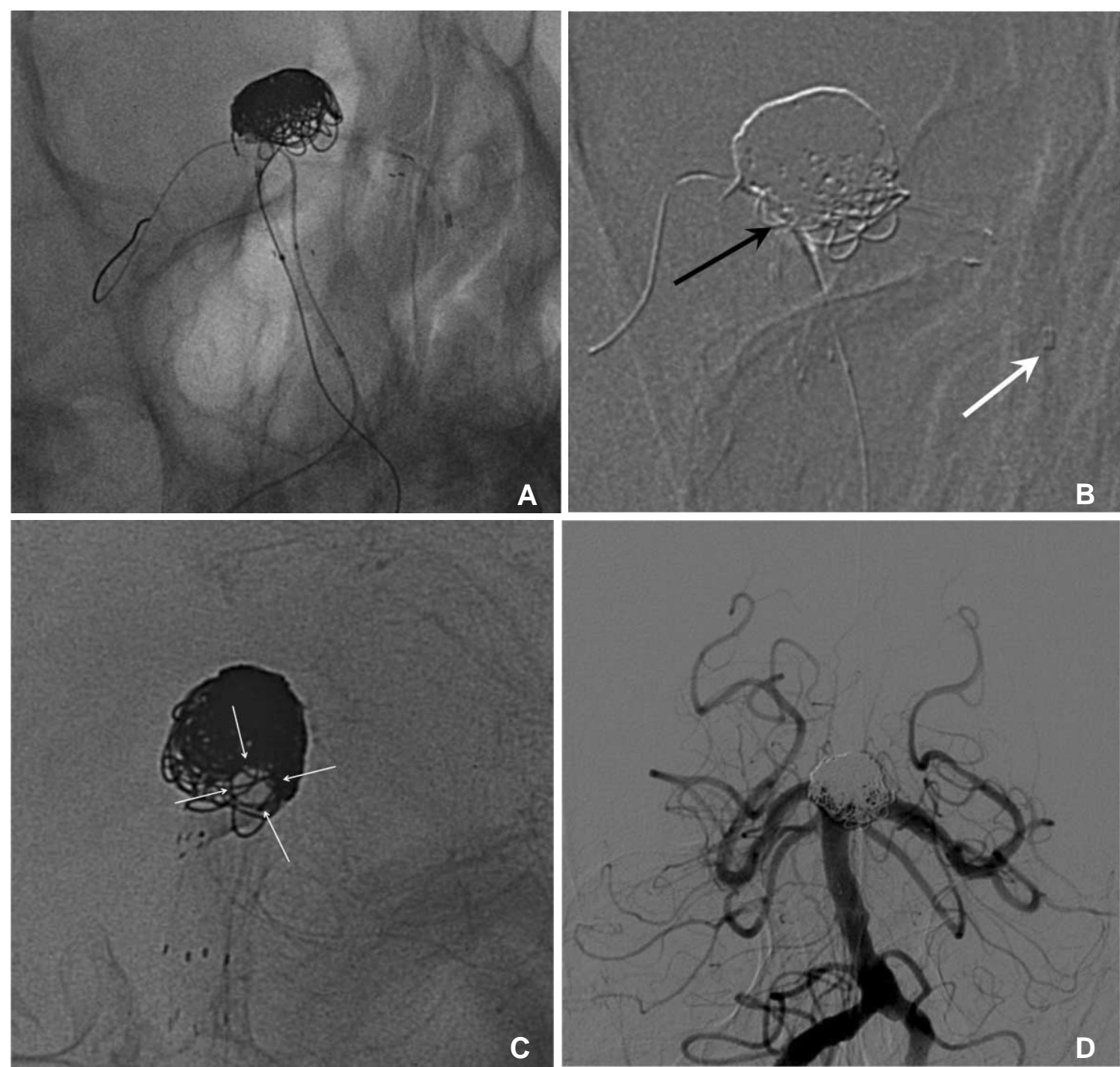

Fig. 10. A large aneurysm at the basilar artery tip.

A. After Enterprise stent placement from BA to left PCA, the prowler plus select catheter is re-navigated to the left PCA over the stent loading wire left in-stent following the 1st stent deployment and a Hyperform balloon is placed at the right PCA through the stent struts.

B. Coiling is completed by balloon- and stent-assisted technique. The black arrow indicates the Hyperform balloon and the white arrow indicates the distal tip of the Prowler plus select microcatheter.

C. The 2 nd Enterprise stent is placed using stent-within-stent technique for the purpose of saving the PCA lumen and promotion of flow diversion. Arrows indicate the patent left PCA.

D. The 18-month follow-up angiogram reveals the stable occlusion state of the aneurysm sac and well preserved both PCAs. 

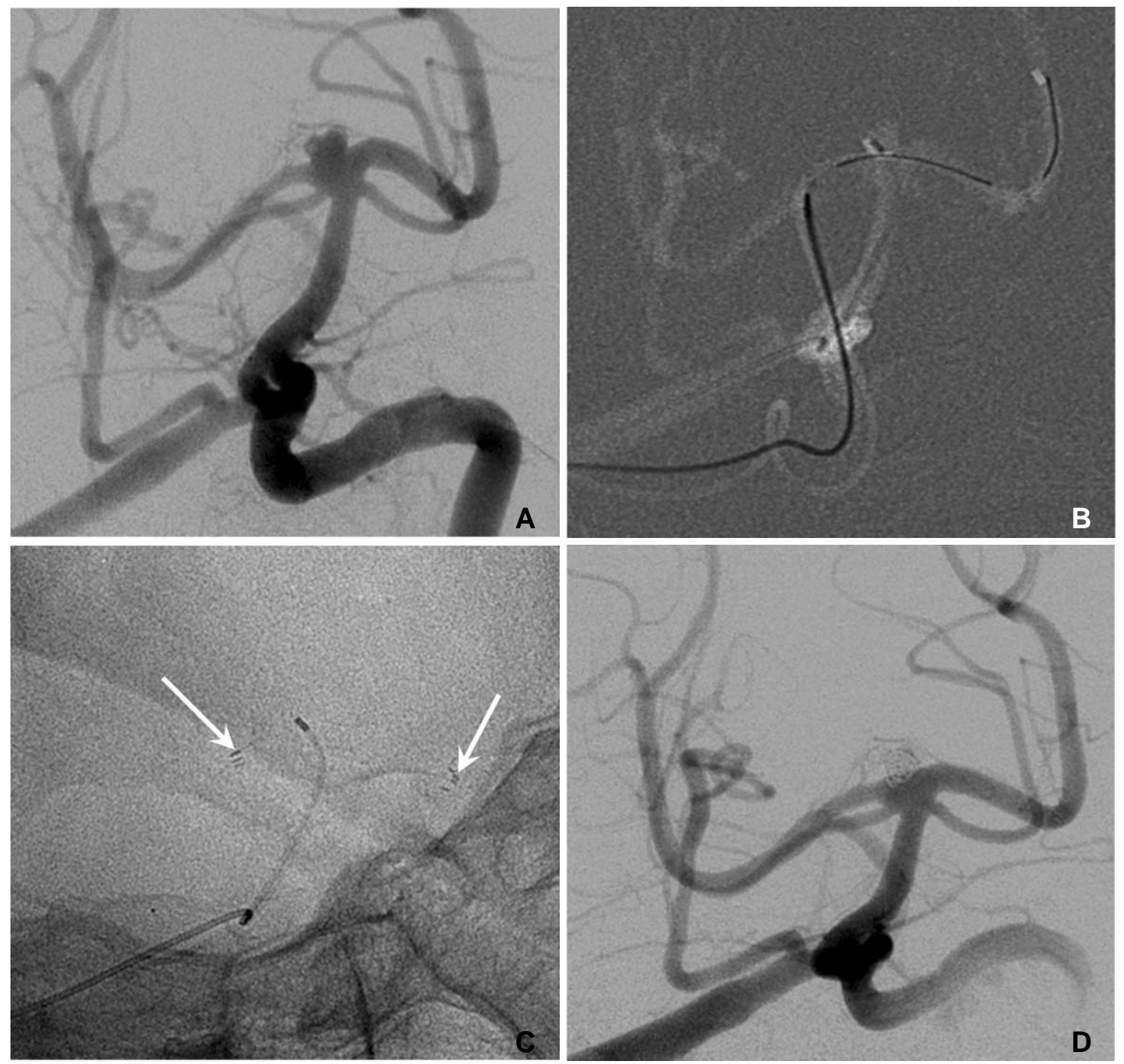

Fig. 11. Horizontal stenting via circle of Willis (courtesy of Prf. Han MH in Seoul National University Hospital).

A. A wide necked basilar tip aneurysm.

B, C. Horizontal placement of an Enterprise stent (arrows) is performed from right PCA to left PCA via right PComA.

D. The final control angiogram reveals complete occlusion of the aneurysm.

possible via bilateral parent artery approach [23] (Fig. 14).

Two stents can also be placed with a linear configuration for a bifurcation aneurysm. In this technique, the proximal ends of both stents are deployed exactly kissing at the bifurcation level, resulting in horizontal configuration of 2 stents with a full coverage of the aneurysm neck [24].

\section{5) Solutions for ultra-wide necked circumferential or fusiform aneurysms}

Fusiform and ultra-wide necked circumferential aneurysms in which the aneurysm sac encompasses the parent artery over 180 degrees are still one of the most challenging lesions. Even though stent-assisted coiling technique has been employed to treat such aneurysms, the coil loops overlapping the parent artery in working projection cannot be avoided, which in turn makes the operator hesitate in coil packing for fear that the coils may encroach on the parent artery lumen. Although down-the-barrel view may often help to differentiate the parent artery lumen from coils [25], it is not always available as a working projection. Flow diverters may be a solution, but unfortunately, they have not yet been introduced in our country. The use of flow-diverting devices may be effective for the treatment of such aneurysms without the use of subsequent coiling [30, 31]. However, recent reports have shown that flow diverters occasionally result in early or delayed rupture of large or giant aneurysms after insertion [32-34]. 


\section{Stent Application for the Treatment of Cerebral Aneurysms}

Although the nature of the mechanism resulting in aneurysm rupture under these conditions is unclear, previous works have suggested that additional coiling may prevent these disastrous events [33, 34]. Additionally, the flow-diverting devices in their current form, may be difficult to be applied especially when the lesion is located distally or in the case of basilar tip aneurysm. This is likely due to both the technical difficulties and the risk of perforator infarctions. Two types of solutions are suggested under the current technology.

\section{a) Balloon-in-stent}

The technique was first described by Fiorrella et al. in 2005 [25]. The stent is placed and then Hyperglide or Hyperform balloon is positioned within the stent. During the coiling, the inflated balloon occupies the stent lumen and therefore, coil loops cannot encroach on the stent lumen. The inflated balloon also prevents the stent to be squashed through the coils are packed as compactly as possible. In addition, circumferential coil packing around the stented parent artery may provoke in-stent thrombosis. The inflated balloon may prevent in-stent thrombosis provoked by circumferential coil packing. Finally, the balloon can be used to "batten down the hatch" if procedural rupture occurs during the coiling [35, 36].

The stent is first deployed and the microcatheter was re-navigated through the stent to a distal portion of the parent artery. By using a 300-cm length exchangeable 0.010-inch wire (X-celerator), Hyperglide or Hyperform balloon is placed within the stent covering the entire aneurysm neck. And then coiling can be performed as a usual balloon-remodeling technique (Fig. 15). If multiple overlapping stents are needed, the exchangeable wire can be exchanged to a 0.014 -inch exchangeable wire, or a 0.016/0.018-inch microwire should be used for navigation of 0.021 -inch microcatheter through the stent lumen $[32,33]$.

b) Stent-assisted coiling followed by overlapping stent(s) Although the balloon-in-stent technique is a valuable
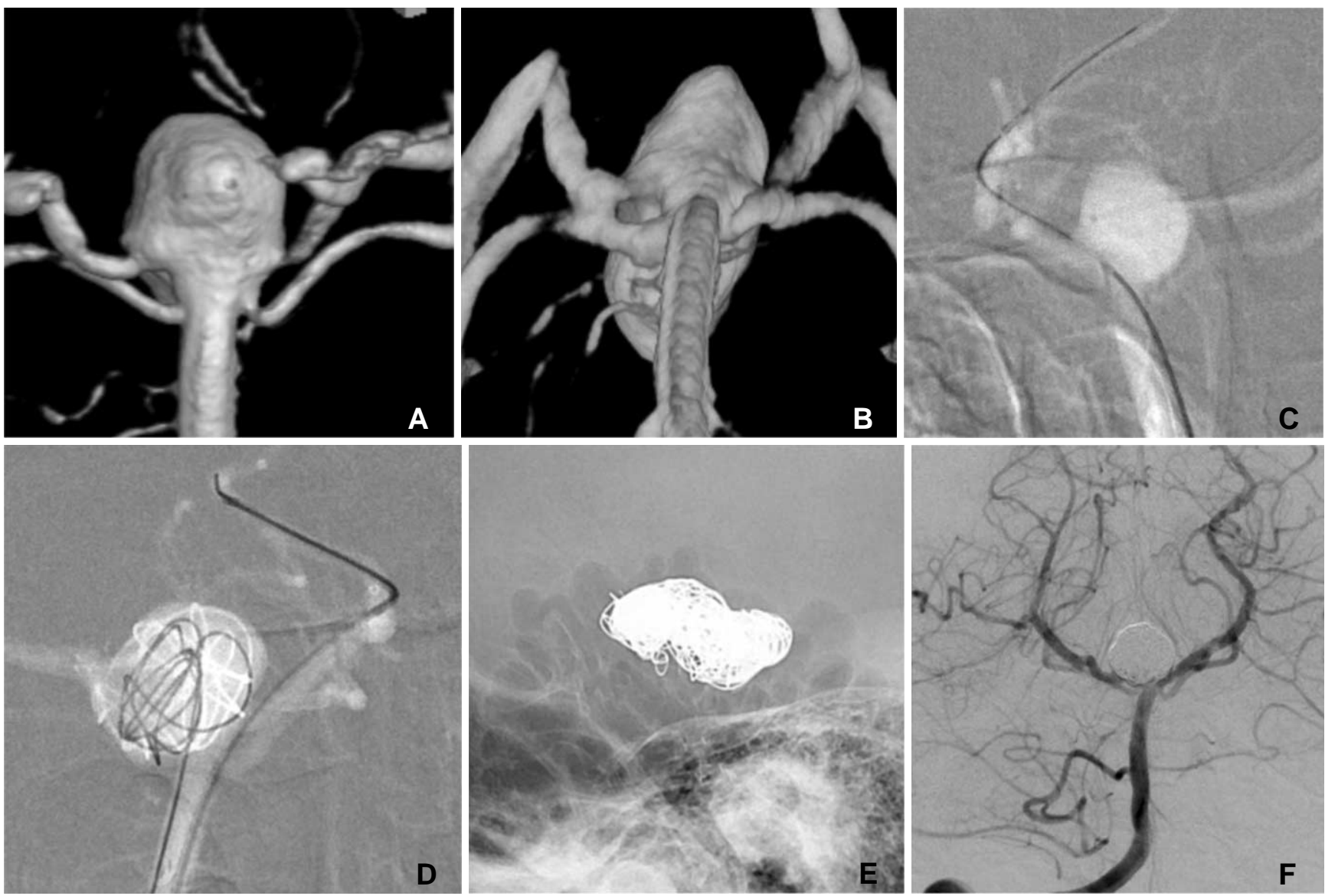

Fig. 12. Y-configuration stents through the struts.

A, B. A large basilar tip aneurysm.

C, D. Coil embolization is performed after placement of 2 stents with Y-configuration through the struts. A native lateral (E) and a control angiogram (F) show complete embolized state of the aneurysm and well preserved bilateral PCAs. 
option for fusiform or ultra-wide necked circumferential aneurysms, it is complex and is occasionally difficult, especially in cases that the stented segment of the parent artery is tortuous. A self-expanding Enterprise stent leaves the stent-loading wire in situ following stent deployment. The presence of the stentloading wire increases the ease with which a second stent can be inserted. Thus, stent-within-stent technique can be employed, whenever needed, without the requirement of an exchange wire. This ability of the Enterprise stent allows for secondary maintenance of the parent artery lumen without requiring the use of an additional balloon during the procedure.

A 0.021 -inch microcatheter is navigated across the aneurysm neck portion to a distal branch of the parent artery. A second microcatheter is inserted into the aneurysm sac, and the initial Enterprise stent was deployed, bridging the aneurysm neck. After the first stent deployment, the microcatheter is re-advanced to the initial position over the stent-loading wire which was left in situ within the deployed stent. Then coil embolization is performed as compactly as possible, including the aneurysm neck portion which encompassed the parent artery more than 180 degrees. Finally, a second Enterprise stent is introduced and is deployed in an overlapping manner. If needed, this procedure is repeated to insert more than 2 overlapping stents (Fig. 16). In case in which blood flow is compromised due to in-stent thrombosis during the coiling, a 2nd stent can easily restore blood flow through the
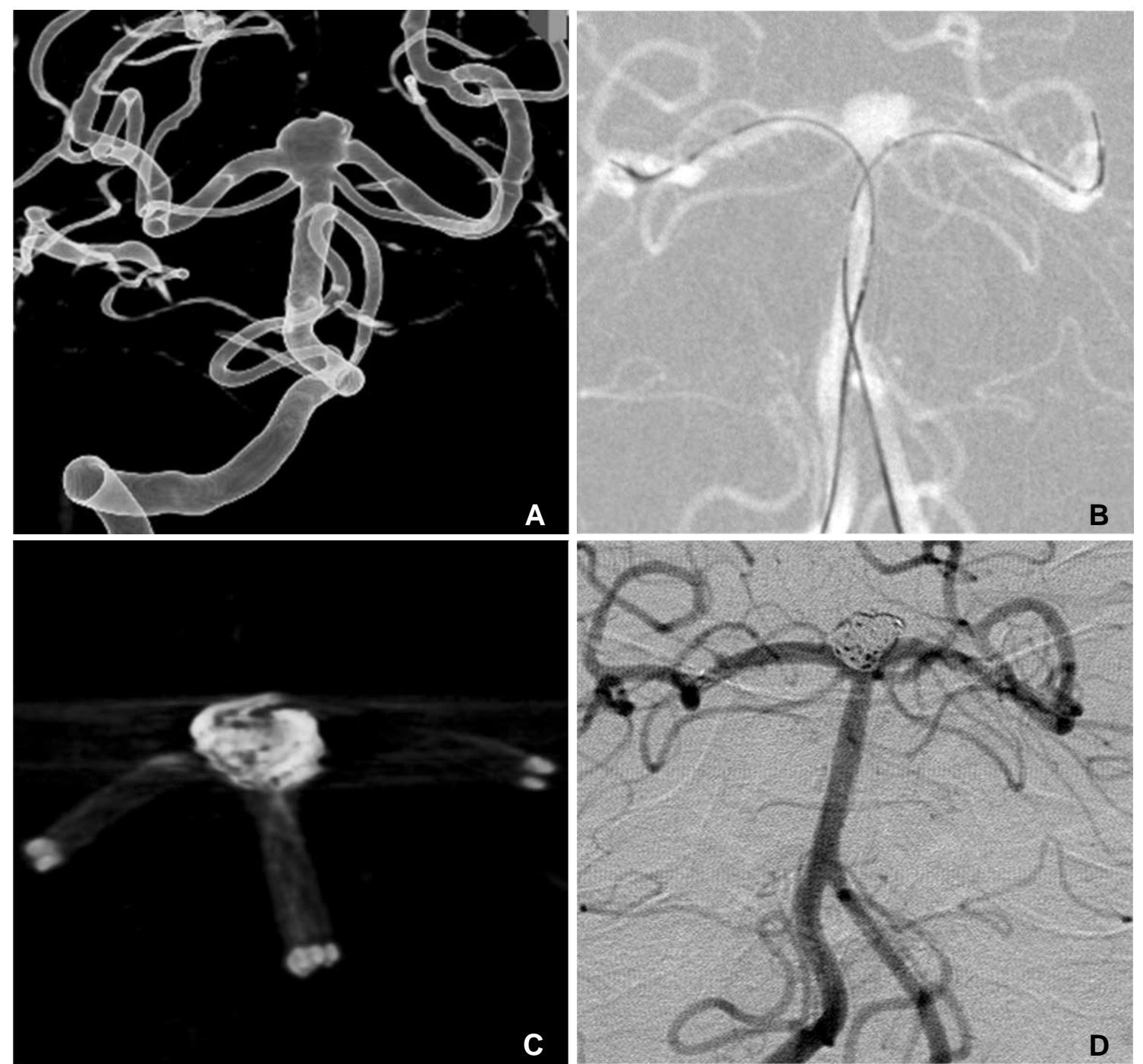

Fig. 13. Kissing 2 stents with Y-configuration (courtesy of Prf. Kim DI in Severance Hospital).

A. A wide-necked aneurysm at the BA tip.

B. Two Prowler plus microcatheters are navigated to both PCAs and 2 Enterprise stents are loaded in the catheters, respectively.

C. Coiling is conducted after simultaneous deployment of 2 Enterprise stents from BA to both PCAs, respectively.

D. The final control angiogram shows near complete occlusion of the aneurysm sac and well preserved both PCAs. 
stented parent artery (Jeon P, unpublished data).

\section{A Clinical Consideration of Stent Use for the Treatment of Cerebral Aneurysms}

As widely explored, stents can positively affect the durability of coiling as well as act as a scaffold for coiling. However, stents also have a shadow of concern that it requires dual antiplatelet medication for at least 3 months and then life-long medication of aspirin, and that a small but non-negligible rate of in-stent stenosis can occur [37]. As previously reported, dual antiplatelet medication may cause serious hemorrhagic complications in a small but non-negligible portion of the patients [38]. In these points, can it be justified to use a stent vigorously for an unruptured aneurysm with clearly very low risk of rupture, such as a very small paraclinoid aneurysm? The decision may belong to the readers who practice the procedure. In contrast, currently available stents make it not only possible, but far easier to treat several types of difficult aneurysms at all locations [39-44]. The easier the procedure, the safer is the procedure. Another important issue is whether stent-assisted coiling can be applied to
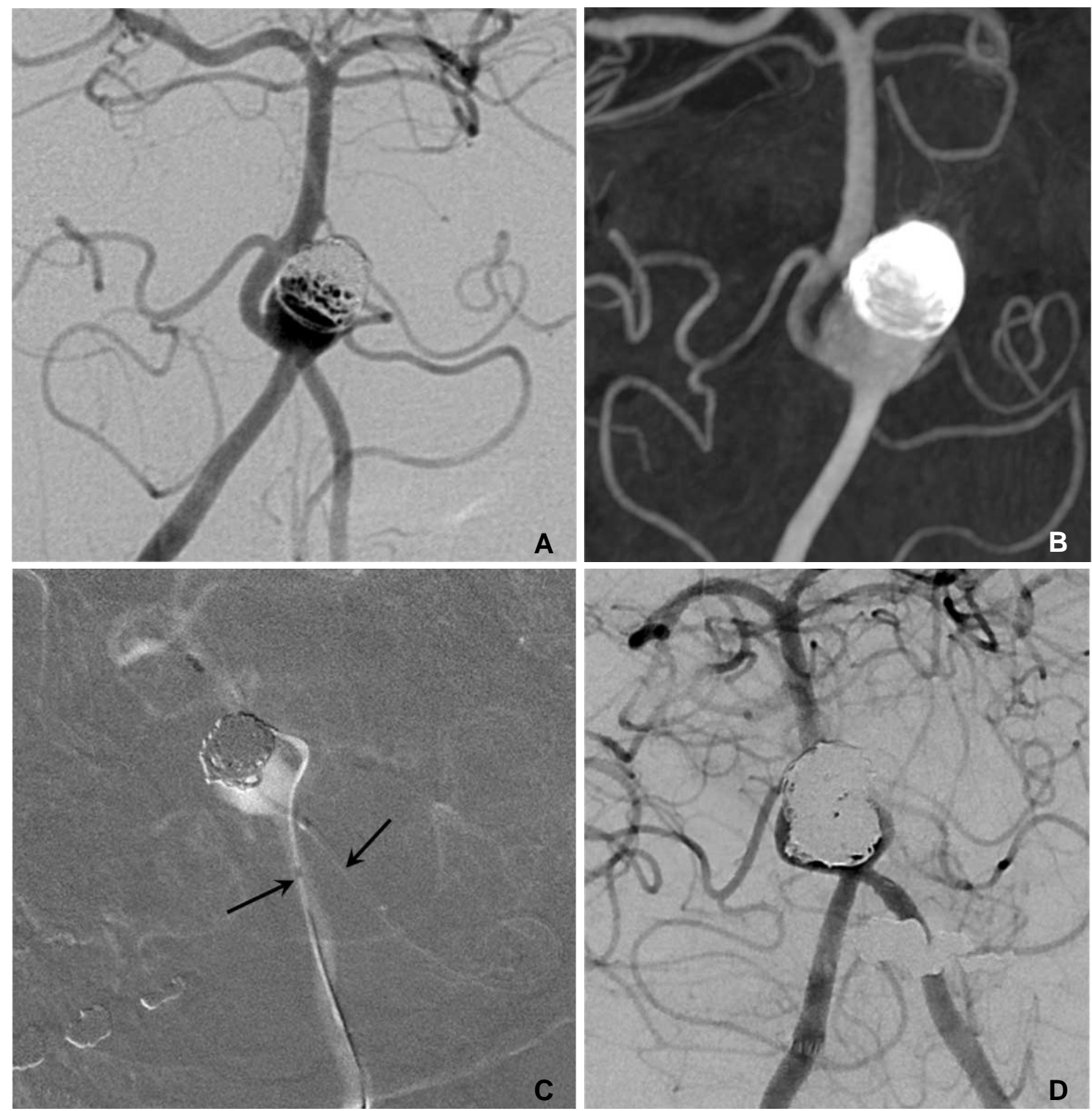

Fig. 14. Two stents with X-configuration (courtesy of Prf. Suh SH in Gangnam Severance Hospital).

A, B. A large recurred aneurysm at the vertebrobasilar fenestration.

C. Two Prowler plus select microcatheters (arrows) are navigated through the both arm of the fenestration, respectively, crossed at the aneurysm neck.

D. After 2 stents are deployed in X-configuration at the aneurysm neck, complete coil embolization is performed. 
ruptured aneurysm. Although increasing body of evidence suggest that stent-assisted coiling can be safely used for ruptured aneurysms in acute period [ 45 , 46], it should be addressed in the future studies with a larger population. The final issue is upto what diameter of the vessel can safely permit placement of currently available stents. Several reports suggest that stenting in vessels less than $2 \mathrm{~mm}$ may be safe, but further evidences should also be needed [44, 47]. Several pioneers have also shown the safety of stent-assisted coiling for anterior communicating artery or posterior inferior cerebellar artery aneurysms, usually less than 2 $\mathrm{mm}$ in diameter [39-44] (Figs. 17, 18). This issue should also be addressed in a larger case series.

In conclusion, we have reason neither to overuse nor to excessively avoid a stent for the treatment of cerebral aneurysms. If we fully understand the properties of currently available stents, are richly experienced
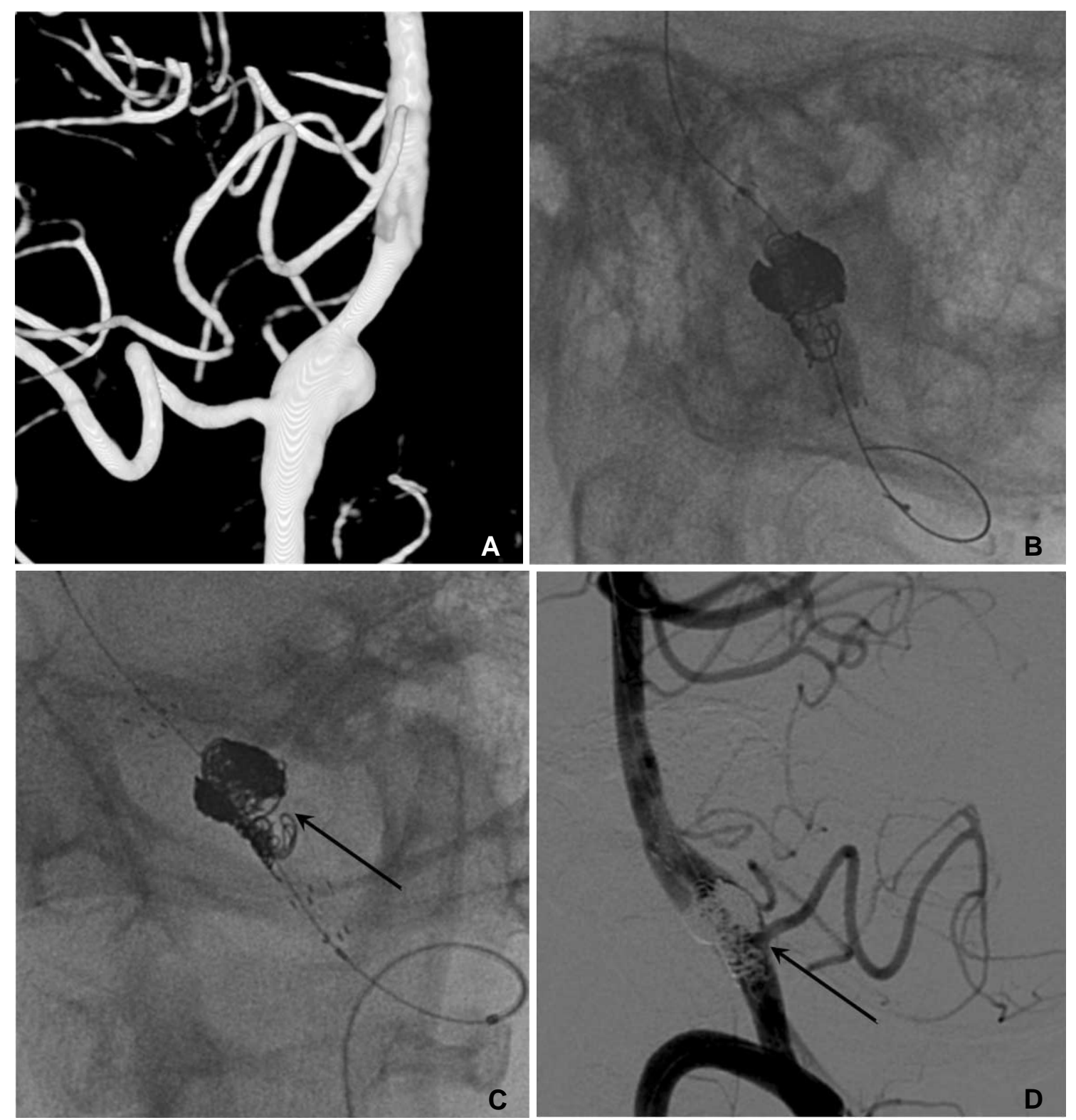

Fig. 15. Balloon-in-stent technique.

A. A ruptured fusiform dissecting aneurysm of left vertebral artery (VA) with involvement of the segment bearing posterial inferior cerebellar artery (PICA) origin.

B. After placement of a Neuroform stent, coiling is conducted with balloon-in-stent-technique.

C. The 2nd Neuroform stent is (arrow) placed with stent-with-stent technique after completion of coiling.

D. The final control angiogram reveals near complete occlusion of the dissecting aneurysm and well preserved VA and PICA. The black arrow indicates the origin of PICA. 

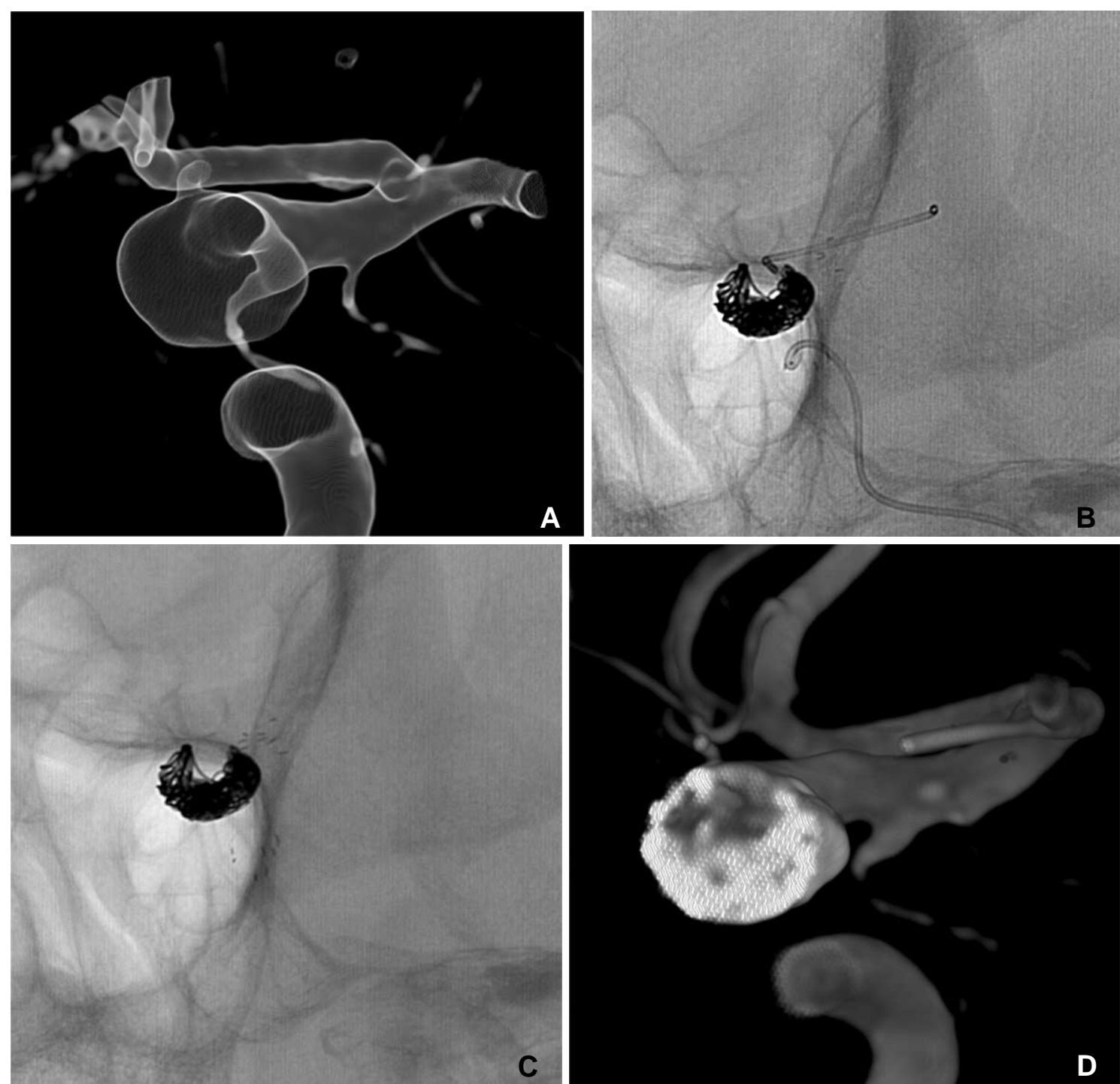

Fig. 16. Multiple overlapping Enterprise stents and coiling.

A. The cross sectional image of 3D reconstruction shows an ultra-wide necked circumferential aneurysm of the ICA ophthalmic region.

B. The 1st Enterprise stent is placed and the Prowler plus select microcatheter is re-navigated over the stent-loading wire left in-stent following the 1 st stent placement. Then the stent-assisted coiling is performed.

C. Finally, the 2nd Enterprise stent is placed with stent-within-stent technique.

D. The cross sectional image of 3D reconstruction shows circumferential coil masses around the parent artery.

in their use, and apply them to appropriately selected cases, stents should improve overall clinical outcomes as well as strengthen the durability of coiling.

\section{References}

1. Higashida RT, Smith W, Gress D, Urwin R, Dowd CF, Balousek $\mathrm{PA}$, et al. Intravascular stent and endovascular coil placement for a ruptured fusiform aneurysm of the basilar artery. Case report and review of the literature. J Neurosurg 1997;87:944-949

2. Lylyk P, Ceratto R, Hurvitz D, Basso A. Treatment of a vertebral dissecting aneurysm with stents and coils: technical case report. Neurosurgery 1998;43:385-388

3. Lylyk P, Cohen JE, Ceratto R, Ferrario A, Miranda C. Combined endovascular treatment of dissecting vertebral artery aneurysms by using stents and coils. J Neurosurg 2001;94:427-432

4. Lylyk P, Cohen JE, Ferrario A, Ceratto R, Miranda C. Partially clipped intracranial aneurysm obliterated with combined stent and coil implantation. J Endovasc Ther 2002;9:160-164

5. Mohammed MI, Sandhu JS, Wakhloo AK. Stent-assisted coil placement in a wide-necked persistent trigeminal artery aneurysm with jailing of the trigeminal artery: a case report. AJNR Am J Neuroradiol 2002;23:437-441

6. Henkes H, Bose A, Felber S, Miloslavski E, Berg-Dammer E, Kü hne D. Endovascular coil occlusion of intracranial aneurysms assisted by a novel self-expandable nitinol microstent (neuroform). Interv Neuroradiol 2002;8:107-119

7. Howington JU, Hanel RA, Harrigan MR, Levy EI, Guterman LR, Hopkins LN. The Neurofrom stent, the first microcatheterdelivered stent for use in the intracranial circulation. Neurosurgery 


\section{Byung Moon Kim, et al.}
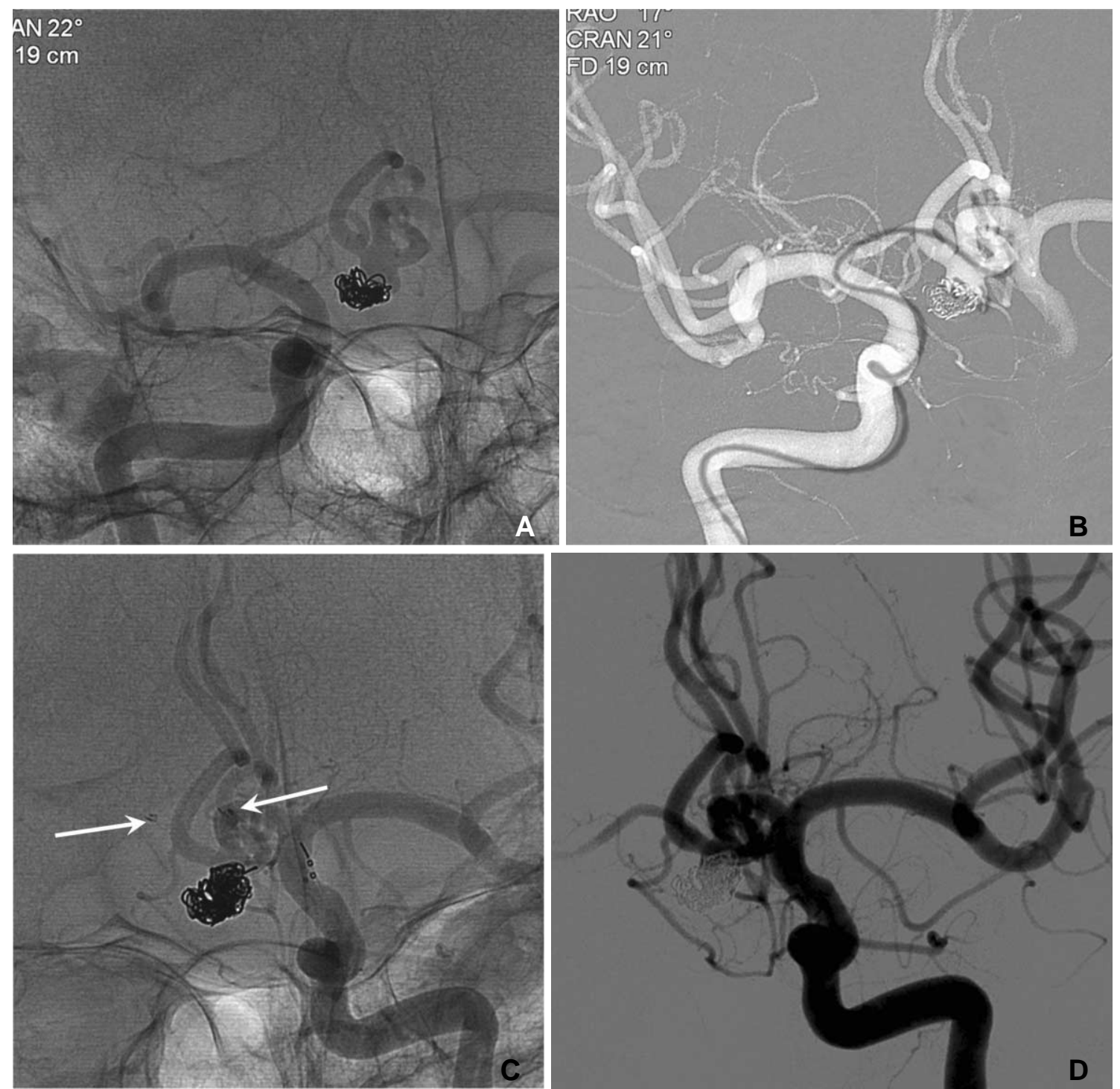

Fig. 17. A. A recurred AcomA aneurysm after coiling (courtesy of Prf. Yoon PH in llsan Hospital).

B. A Prowler plus microcatheter is navigated to left ACA A2 portion across the aneurysm neck via right ACA A1.

C. Coiling is performed after placement of an Enterprise stent (arrows) from right ACA A1 to left ACA A2 portion.

D. The final control angiogram reveals near complete occlusion of the aneurysm sac.

\section{4;54:2-5}

8. Fiorella D, Albuquerque FC, Han P, Mcdougall CG. Preliminary experience using the Neuroform stent for the treatment of cerebral aneurysms. Neurosurgery 2004;54:6-16

9. Krischek O, Miloslavski E, Fischer S, Shrivastava S, Henkes H. A comparison of functional and physical properties of self-expanding intracranial stents [Neuroform3, Wingspan, Solitaire, Leo(+), Enterprise]. Minim Invasive Neurosurg 2011;54:21-28

10. Spelle L, Piotin M, Mounayer C, Moret J. Saccular aneurysms: endovascular treatment-devices, techniques and strategies, management of complications, results. Neuroimaging Clin N Am 2006;16:413-451

11. Biondi A, Janardhan V, Katz JM, Salvaggio K, Riina HA, Gobin YP. Neuroform stent-assisted coil embolization of wide-neck intracranial aneurysms: strategies in stent deployment and midterm follow-up. Neurosurgery 2007;61:460-468

12. Hong B, Patel NV, Gounis MJ, DeLeo MJ 3rd, Linfante I, Wojak JC, et al. Semi-jailing technique for coil embolization of complex, wide-necked intracranial aneurysms. Neurosurgery 2009;65:11311138

13. Gao X, Liang G, Li Z, Qu H, Wei X. Stent-assisted coil embolization of wide-necked intracranial aneurysms using a semi-deployment technique: angiographic and clinical outcomes in 31 consecutive patients. Interv Neuroradiol 2010;16:385-393

14. Thorell WE, Chow MM, Woo HH, Masaryk TJ, Rasmussen PA. Y-configured dual intracranial stent-assisted coil embolization for the treatment of wide-necked basilar tip aneurysms. Neurosurgery 2005;56:1035-1040

15. Rohde S, Bendszus M, Hartmann M, Hähnel S. Treatment of a wide-necked aneurysm of the anterior cerebral artery using two 


\section{Stent Application for the Treatment of Cerebral Aneurysms}
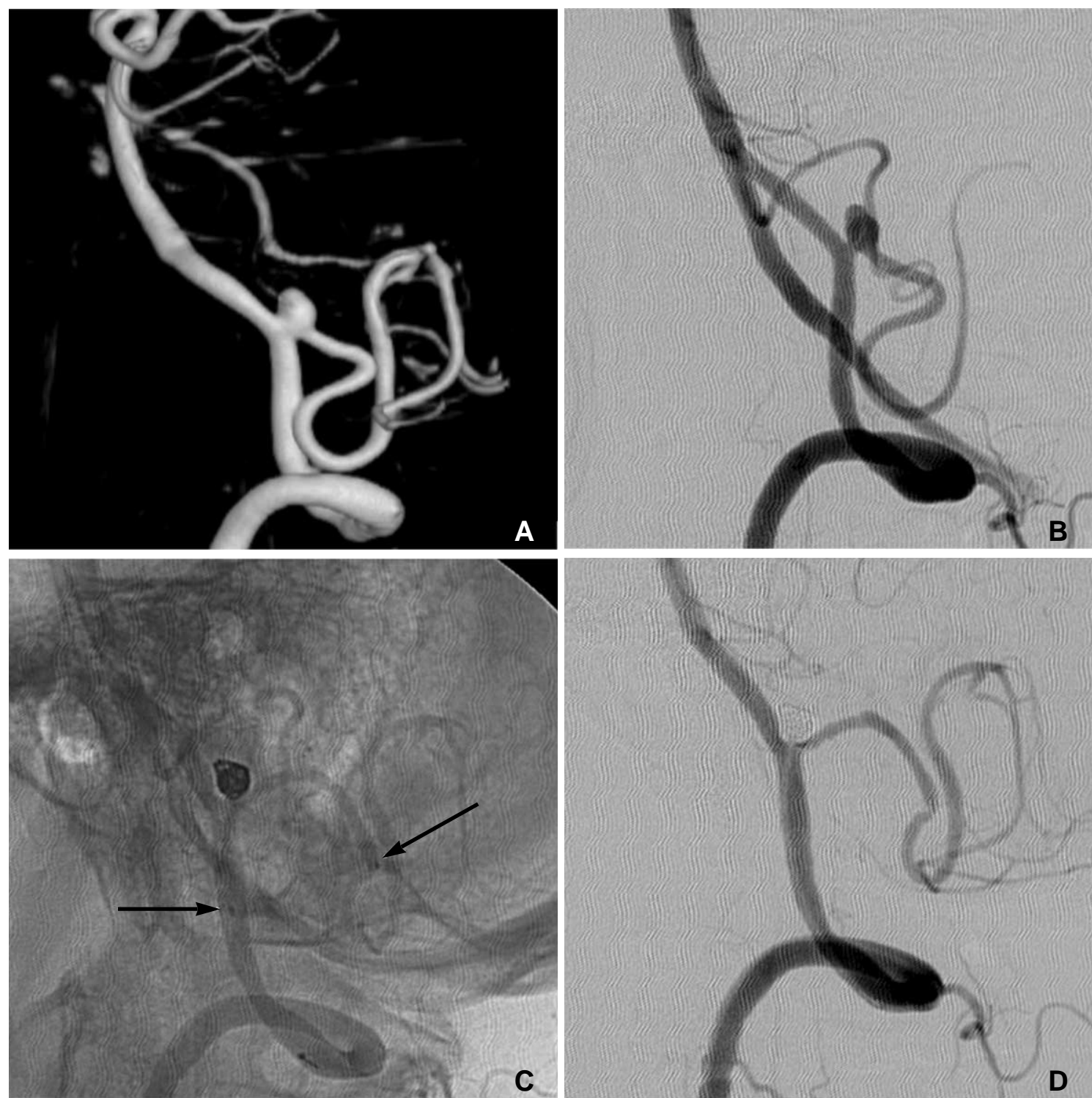

Fig. 18. A, B. Images of 3D reconstruction and working projection show a wide necked aneurysm at the left VA-PICA origin.

C. Stent-assisted coiling is performed. Arrows indicate proximal and distal markers of the Enterprise stent.

D. The final control angiogram reveals complete occlusion of the aneurysm sac and widening of VA-PICA angle.

Enterprise stents in "Y"-configuration stenting technique and coil embolization: a technical note. Neuroradiology 2010;52:231-235

16. Lozen A, Manjila S, Rhiew R, Fessler R. Y-stent-assisted coil embolization for the management of unruptured cerebral aneurysms: report of six cases. Acta Neurochir (Wien) 2009;151: 1663-1672

17. Spiotta AM, Gupta R, Fiorella D, Gonugunta V, Lobo B, Rasmussen PA, et al. Mid-term results of endovascular coiling of wide-necked aneurysms using double stents in "Y-configuration". Neurosurgery 2011 Mar [Epub ahead of print]

18. Yang TH, Wong HF, Yang MS, Ou Ch, Ho TL. "Waffle cone" technique for intra/extra-aneurysmal stent placement for the treatment of complex and wide-necked bifurcation aneurysm. Interv Neuroradiol 2008;14 Suppl 2:49-52

19. Sychra V, Klisch J, Werner M, Dettenborn C, Petrovitch A,
Strasilla C, et al. Waffle-cone technique with Solitaire AB remodeling device: endovascular treatment of highly selected complex cerebral aneurysms. Neuroradiology 2010 Sep [Epub ahead of print]

20. Kelly ME, Turner R, Gonugunta V, Woo HH, Rasmussen PA, Masaryk TJ, et al. Stent reconstruction of wide-necked aneurysms across the circle of Willis. Neurosurgery 2007;61(5 Suppl2):249-254

21. Siddiqui MA, Bhattacharya J, Lindsay KW, Jenkins S. Horizontal stent-assisted coil embolization of wide-necked intracranial aneurysms with the Enterprise stent-a case series with early angiographic follow-up. Neuroradiology 2009;51:411-418

22. de Paula Lucas C, Piotin M, Spelle L, Moret J. Stent-jack technique in stent-assisted coiling of wide-neck aneurysms. Neurosurgery 2008;62(5 Supple 2):ONS414-416

23. Menendez JY, Harrigan MR. X-configuration stent-assisted 


\section{Byung Moon Kim, et al.}

coiling. World Neurosurg 2010;74:143-144

24. Lubicz B. Linear stent-assisted coiling: another way to treat very wide-necked intracranial aneurysms. Neuroradiology 2011;53: 457-459

25. Fiorella D, Albuquerque FC, Masaryk TJ, Rasmussen PA, McDougall CG. Balloon-in-stent technique for the constructive endovascular treatment of "ultra-wide necked" circumferential aneurysms. Neurosurgery 2005;57:1218-1227

26. Park SI, Kim BM, Kim DI, Shin YS, Suh SH, Chung EC, et al. Clinical and angiographic follow-up of stent-only therapy for acute intracranial vertebrobasilar artery dissecting aneurysms. AJNR Am J Neuroradiol 2009;30:1351-1356

27. Heller RS, Malek AM. Delivery technique plays an important role in determining vessel wall apposition of the Enterprise selfexpanding intracranial stent. J Neurointervent Surg 2011 Jul [Epub]

28. Kim BM, Park SI, Kim DJ, Kim DI, Suh SH, Kwon TH, et al. Endovascular coil embolization of aneurysms with a branch incorporated into the sac. AJNR Am J Neuroradiol 2010;31:145151

29. Kwon OK, Kim SH, Kwon BJ, Kang HS, Kim JH. Oh CW, et al. Endovascular treatment of wide-necked aneurysms by using two microcatheters: techniques and outcomes in 25 patients. AJNR Am J Neuroradiol 2005;26:894-900

30. Fiorella D, Woo HH, Albuquerque FC, Nelson PK. Definitive reconstruction of circumferential, fusiform intracranial aneurysms with the pipeline embolization device. Neurosurgery 2008;62: 1115-20

31. Fiorella D, Kelly ME, Albuquerque FC, Nelson PK. Curative reconstruction of a giant midbasilar trunk aneurysm with the pipeline embolization device. Neurosurgery 2009;64:212-17

32. Turowski B, Macht S, Kulcsár Z, Hänggi D, Stummer W. Early fatal hemorrhage after endovascular cerebral aneurysm treatment with a flow diverter (SILK-Stent): do we need rethink our concepts? Neuroradiology 2011;53:37-41

33. Kulcsár Z, Houdart E, Bonafé A, Parker G, Millar J, Goddard AJ, et al. Intra-aneurysmal thrombosis as a possible cause of delayed aneurysm rupture after flow-diversion treatment. AJNR Am J Neuroradiol 2011;32:20-25

34. Lubicz B, Collignon L, Raphaeli G, Pruvo JP, Bruneau M, De Witte O, et al. Flow-diverter stent for the endovascular treatment of intracranial aneurysms: a prospective study in 29 patients with 34 aneurysms. Stroke 2010;41:2247-2253

35. Suh SH, Kim BM, Park SI, Kim DI, Shin YS, Kim EJ, et al. Stentassisted coil embolization followed by a stent-within-a-stent technique for ruptured dissecting aneurysms of the intracranial vertebrobasilar artery. J Neurosurg 2009;111:48-52

36. Lee BH, Kim BM, Park MS, Park SI, Chung EC, Suh SH, et al. Reconstructive endovascular treatment of ruptured blood blisterlike aneurysms of the internal carotid artery. J Neurosurg 2009; 110:431-436

37. Fiorella D, Albuquerque FC, Woo H, Rasmussen PA, Masaryk TJ, McDougall CG. Neuroform in-stent stenosis: incidence, natural history, and treatment strategy. Neurosurgery 2006;59:34-42

38. Kim DJ, Suh SH, Kim BM, Kim DI, Huh SK, Lee JW. Hemorrhagic complications related to the stent-remodeled coil embolization of intracranial aneurysms. Neurosurgery 2010;67: 73-78

39. Kim BM, Kim DI, Park SI, Kim DJ, Suh SH, Won YS. Coil embolization of unruptured middle cerebral artery aneurysms. Neurosurgery 2011;68:346-353

40. Rasian A, Oztaskin M, Thompson E, Dogan A, Petersen B, Nesbit G, et al. Neuroform stent-assisted embolization of incidental anterior communicating aneurysms: long-term clinical and angiographic follow-up. Neurosurgery $2011 \mathrm{Feb}$ [Epub ahead of print]

41. Huang Q, Xu Y, Hong B, Zhao R, Zhao W, Liu J. Stent-assisted embolization of wide-neck anterior communicating artery aneurysms: review of 21 consecutive cases. AJNR Am J Neuroradiol 2009;30:1502-1506

42. Vendrell JF, Costalat V, Brunel H, Riquelme C, Bonafe A. Stentassisted coiling of complex middle cerebral artery aneurysms: initial and midterm results. AJNR Am J Neuroradiol 2011;32:259-263

43. Yang P, Liu J, Huang Q, Zhao W, Hong B, Xu Y, Zhao R. Endovascular treatment of wide-neck middle cerebral artery aneurysms with stents: a review of 16 cases. AJNR Am J Neuroradiol 2010;31:940-946

44. Turk AS, Niemann DB, Ahmed A, Aagaard-Kienitz B. Use of self-expanding stents in distal small cerebral vessels. AJNR Am J Neuroradiol 2007;28:533-536

45. Tä htinen OI, Vanninen RL, Manninen HI, Rautio R, Haapanen A, Niskakangas T, et al. Wide-necked intracranial aneurysms: treatment with stent-assisted coil embolization during acute $(<72$ hours) subarachnoid hemorrhage-experience in 61 consecutive patients. Radiology 2009;253:199-208

46. Lodi YM, Latorre JG, El-Zammar Z, Swarnkar A, Deshaies E, Fessler RD. Stent assisted coiling of the ruptured wide necked intracranial aneurysm. J Neurointervent Surg 2011 Jul [Epub]

47. Zhang J, Lv X, Jiang C, Li Y, Yang X, Wu Z. Endovascular treatment of cerebral aneurysms with the use of stents in small cerebral vessels. Neurol Res 2010;32:119-122 